\title{
Analysis of Static and Dynamic Efficiency for Sustainable Growth of Edu-Tech Companies
}

\author{
Hyunwoo Goh \\ Dept. of Logistics System Engineering, Seokyeong University \\ 16-1 Jungneung-Dong, Sungbuk-Ku, Seoul 136-704, KOREA, USA \\ skuie@naver.com
}

\begin{abstract}
The advent of the Fourth Industrial Revolution is opening new opportunities for many industries. With the emergence of a new type of industry (named Edu-Tech) incorporating ICT technology in the education industry, EduTech companies need to be competitive to continuously grow. Therefore, this study intends to help improve competitiveness by analyzing and evaluating the efficiency of Edu-Tech companies. In particular, it analyzes not only static efficiency but also dynamic efficiency analysis and evaluation to evaluate basic efficiency and efficiency trends and stability. DEA (data envelopment analysis) and DEA / Window are used for research.
\end{abstract}

Keywords: Efficiency, Data Envelopment Analysis (DEA), DEA/Window, EduTech.

\section{Introduction}

Technological advancements around the world are rapidly changing the education system. By 2016, 58 million students have participated in the "Massive Open Online Curse," which is well known as "MOOC," and is fundamentally changing the way of education. It is also predicted that VR (virtual reality) and AR (augmented reality) technologies will revolutionize learning experiences and space in the future. Also, it is expected that the pattern of education will change significantly in Korea due to a decrease in the school-age population. In the future, the representative public educational institution, the school, said, "Education to teach the contents can be acquired through AI (artificial intelligence) or online. The assistant role will become more important." Besides, it has been suggested that education is not a problem that can be completely replaced by AI, and that the role of teachers in the field of personality, which is difficult to replace by AI, will be 
greater. In the future, homeschooling will increase, and since the educational space can be expanded out of school, it is highly likely that other functions will be reduced in addition to the ability to maintain affiliation (STEPI, 2019).

On the issue of private education, most experts agreed that private education would remain at the current level or increase somewhat, even if the population declined due to a decrease in population. In the public survey, $77.2 \%$ of the respondents said that private education will increase. Experts predict that the form of private education may change in the future, but private education will continue to exist. Even if the school-age population decreases and the number of colleges decreases, private colleges will not be able to decrease in an entrance-oriented society, because good colleges are limited and demand remains. If there is a part where the demand for entrance exams decreases due to a decrease in the school-age population, there is a possibility that the curriculum of private education will be further subdivided into higher costs. In recent years, school education is moving toward the development of personal aptitude and aptitude more actively, but there are limitations in that it is difficult for schools to meet each student's needs because each individual's competency and interests are different. Even if the school-age population decreases, the demand for the private education market is likely to remain alive as the education sector will expand into entertainment and sports education, vocational education, lifelong education, etc., and develop in a more detailed and specialized form. Already, private education companies are considering developing customized products to create high added value. Decreasing the schoolage population will induce personalization, and parents' desire for their children's competitive advantage may further shake the order of public education or move to private education.

Recently, the domestic Edu-Tech (a compound word of Education and Technology) is undergoing a second transformation. Since 2017, a large number of second-generation education companies such as startups have emerged, and a new ecosystem has been created. Unlike the first-generation education companies that started at supplementary learning academies in alleys, they entered a niche market with educational services utilizing various smart mobile technologies. Content has also diversified from traditional foreign language learning to consulting, coaching, communication, monitoring, coding education, early childhood cognitive development, and learning support, and is also introducing AI and VR technologies.

STUniTas, which is a small and medium-sized company starting from startups, is developing learning information of college and university candidates as big data. It launched a short-term high-scoring service that analyzed the domestic government official exam data, attracting demand, and also started a TPR service to predict the likelihood of passing a U.S. university by acquiring Princeton Review, a US university entrance company. Edu-Tech startups are aggressive in targeting the market by attracting external investment from the beginning. Edu-Tech startups are 
flocking up from 400 million won to as much as 4 billion won. Smart Study also started in 2010 as an Edu-Tech startup. As the Pink Pong and Baby Shark characters burst, the company's current corporate value evaluation reaches 200 billion won. In preparation for listing this year, he received an equity investment of 10 billion won. "The domestic education market is shrinking every year due to low fertility and low growth," said Bisang-gyoyug Edu-Tech Company CEO. "Students who took the college entrance exam immediately fell sharply from 600,000 in 2014 to 480,000 in 2019. In this environment, turning to the overseas market has become an essential survival strategy for education companies. " He continued, "Korean education content and platforms are rapidly localized thanks to the integration of information and communication technologies. It will be a strength in preoccupying the future smart education market." Korea is the world's first country to enact the e-Learning Industry Development Act, and through this, the distance education industry such as cyber university and internet lectures has greatly developed. The industry expects the domestic Edu-Tech market to grow to 10 trillion won this year. However, the point that Korean Edu-Tech companies are clinging to high-demand private education and entrance exam content is an improvement. The task of Korean EduTech companies to deviate from this framework is to limit the role of complementing private education such as language, entrance examination, and employment, unlike foreign companies that implement various contents.

Edu-Tech startups are also booming abroad. This is because AI, VR, and AR (augmented reality) technologies are commercialized and ICT is developing rapidly. The U.S. Edu-Tech market grew by an average of over $8 \%$ each year, surpassing $\$ 42.9$ billion in 2018. Global industry analysts (GIA), a US market research firm, predicts that the global Edu-Tech market will grow to $\$ 430$ billion this year. In China, the government is taking the lead in modernizing education and focusing on the Edu-Tech industry. This is because the development of a digital online education system is indispensable to provide a uniform education service due to the large population, vast land, and wide variations in infrastructure in each region. This is also the reason why many educational tech companies that are famous all over the world come from China. Accordingly, the infinite competition began to preoccupy the global Edu-Tech market. American IT giants also jumped into the education business. Google has developed an Expedition, an immersive education app, and provides experiential VR / AR content. In addition, Google Chromebook and GSuite for Education services that support learning materials and teacher work are dominating the US school scene. Microsoft (MS) is also launching an ICT-based education management system that supports school work. Amazon also provides a system for teachers to easily obtain and share educational content. The UK is looking for ways to reduce school workload and develop and distribute support systems. In particular, we focus on developing software coding education content in cooperation with Edu-Tech private companies. Thanks to this support, one out of 
two Edu-Tech startups in Europe is born in the UK. The UK expects the Edu-Tech market to grow to $£ 30$ billion in 2020. In the new Edu-Tech field, which combines education and ICT technology that has emerged as a new blue ocean market both at home and abroad, domestic companies need to utilize their resources efficiently to be competitive and preoccupy the market.

This study is to measure how the efficiency of domestic Edu-Tech companies change overtime for 5 years from 2015 to 2018 and to find ways to grow into a competitive company. First, we analyze the static efficiency of DEA and compare and analyze the stability of Edu-Tech's efficiency change and efficiency fluctuation by using the widely used DEA / window model to overcome the static characteristics. DEA / window analysis is a time-dependent DEA technique first proposed in 1985 and is widely used as a method of comparing the efficiency change and the stability of the change. Therefore, based on the analysis results, it is expected that it will be a standard for finding fundamental and sustainable policies by identifying the inherent problems of Edu-Tech companies.

\section{Concept of DEA}

DEA is an application technique of linear programming. It is a technique for evaluating the relative efficiency between groups with similar input and output types, and measuring the relative efficiency between Decision-Making Units (DMUs) using multiple inputs and output variables. DEA was first introduced by Charnes, Cooper, and Rhodes in 1978.

DEA measures the relative effectiveness of each group from the ratio of the group's weighted sum of inputs and total of outputs. The efficiency score is calculated by selecting the weight that maximizes the ratio of the linear combination of output factors to the linear combination of input factors. The DEA ration form is designed to measure the relative efficiency or productivity of a specific DMUk. The DEA formulation is given as follows (Goh, 2015).

When there is a set of $\mathrm{n}$ DMUs to be analyzed, each of which uses $\mathrm{m}$ common inputs and $\mathrm{s}$ common outputs. Let $\mathrm{k}(\mathrm{k}=1, \ldots, \mathrm{n})$ denote the DMUs whose relative efficiency or productivity is to be maximized (Goh, 2015).

$$
\max h_{k}=\frac{\sum_{r=1}^{s} u_{r k} Y_{r k}}{\sum_{i=1}^{m} v_{i k} X_{i k}}
$$

s. t.

$$
\begin{gathered}
\frac{\sum_{r=1}^{s} u_{r k} Y_{r k}}{\sum_{i=1}^{m} v_{i k} X_{i k}} \leq 1, \text { for } j=1, \ldots, n \\
u_{r k} \geq 0, \text { for } r=1, \ldots, s
\end{gathered}
$$




$$
v_{i k} \geq 0, \text { for } i=1, \ldots, m
$$

Where $u_{r k}$ : the variable weight is given to the $r^{\text {th }}$ output of the $k^{\text {th }}$ DMU $v_{i k}$ : the variable weight is given to the $i^{\text {th }}$ output of the $k^{\text {th }}$ DMU

$u_{r k}$ and $v_{i k}$ : decision variables determining the relative efficiency of $D M U_{k}$ $Y_{r j}:$ the $r^{\text {th }}$ output of the $j^{\text {th }}$ DMU

$X_{i j}$ : the $i^{\text {th }}$ input of the $j^{\text {th }} \mathrm{DMU}$

$Y_{r j}$ and $X_{i j} \geq 0$

$h_{k} \leq 1$.

When the efficiency score $h_{k}$ is $1, D M U_{k}$ is regarded as an efficient frontier.

\section{DEA/Window}

So far, most DEA analyzes have mainly focused on cross-sectional analysis, which measures efficiency only based on inputs and outputs at a specific point in time. However, measuring efficiency in this way has the weakness that dynamic changes in efficiency cannot be considered due to changes in the environment. It was DEA / Window analysis developed by Charnes et al. (1985) that appeared as a way to compensate for this weakness.

Once the data from the DMU is collected by a period in DEA, the efficiency of the period can be roughly understood from a time-series perspective. However, it is difficult to directly compare the efficiency scores of a specific period with the efficiency scores of different periods of each DMU. So Charnes et al. should determine the width of the period (called a window) to observe dynamic changes after collecting data for a period of time. In each window, even the same DMU is considered as a different DMU if the period is different.

For DEA / Window analysis, DEA analysis can be performed using moving averages to check trends and stability. You need to determine the width of the period for this. If the window width is $\mathrm{p}$ and the analysis period is $\mathrm{k}, \mathrm{p}$ is determined using equation (2).

$$
p= \begin{cases}\frac{k+1}{2} & \text { kis odd } \\ \frac{k+1}{2} \pm \frac{1}{2} & \text { kis even }\end{cases}
$$

The number of windows $(w)$ is $w=k-p+1$ as in Table 1 . When the width (p) of the window is determined, the window efficiency evaluation is sequentially analyzed through the moving average. That is when the number of DMUs is $\mathrm{n}, \mathrm{pn}$. DMUs from period 1 to $\mathrm{p}$ are targeted in the first window, and pn DMUs from period 2 to $p+1$ are targeted in the second window. Move back one period and evaluate to the last window. After evaluating efficiency by the window, it is possible to analyze the trend, stability, seasonal behavior of each DMU efficiency 
based on the result.

Window analysis can also be used even if the number of DMUs is small compared to the number of input and output elements. This is because, even if the number of DMUs is $n$, the number of DMUs to be evaluated in each window is increased to $\mathrm{pn}$ if the window width is determined as $\mathrm{p}$.

Table 1: Number of DEA-Window

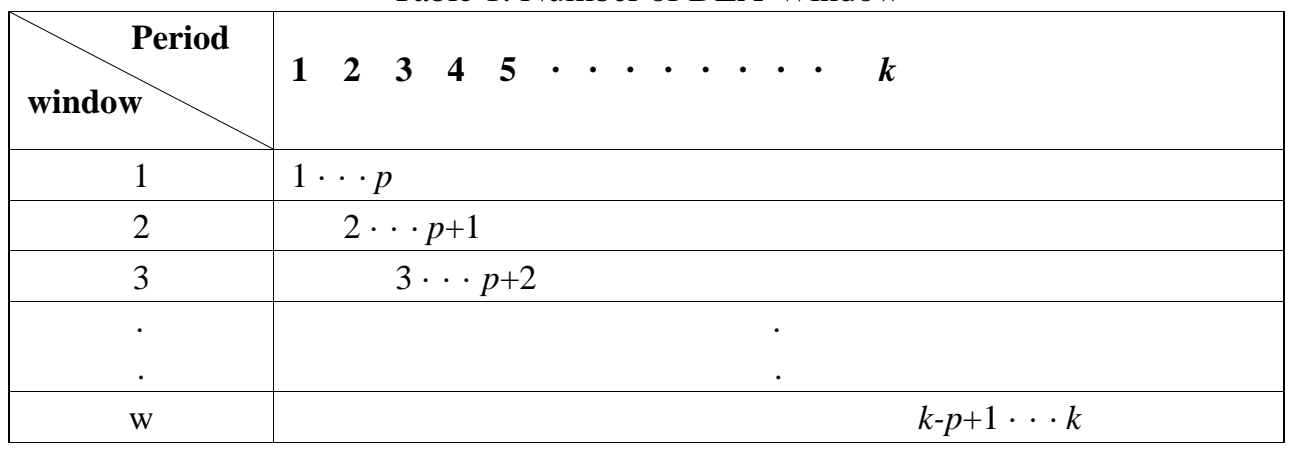

If the number of DMUs is $n$, the characteristics of DEA-Window can be obtained as shown in Table 2.

Table 2: Characteristics of DEA-Window

\begin{tabular}{|c|c|}
\hline Number of windows & $w=k-p+1$ \\
\hline Number of DMUs for each Window & $\mathrm{np}$ \\
\hline Total Number of DMUs & $\mathrm{npw}$ \\
\hline Width of the Window & $p= \begin{cases}\frac{k+1}{2} & \text { kis odd } \\
\frac{k+1}{2} \pm \frac{1}{2} & \text { kis even }\end{cases}$ \\
\hline
\end{tabular}

\section{Efficiency analysis of Edu-Tech company}

\subsection{Factor selection and data collection}

To analyze the static/dynamic efficiency of Edu-Tech companies using DEA, it is very important to select the appropriate input and output factors first. Until recently, there have been many studies applying DEA at home and abroad, but there have been no cases where Edu-Tech companies have been studied. However, in the study using DEA, elements were selected by mixing objective and subjective data. The objective data is publicly published data and emphasizes transparency using financial statements. Subjective data has the advantage of reflecting the characteristics of the target company but may lack objectivity. 
In this study, input/output factors were selected using the financial statements of companies. As an analysis target company, Edu-Tech company with management performance of over 5 years listed on KRX (KoRea eXchange) was selected. The input factors were assets, liabilities, and capital, and the output factors were sales, operating profit, and net profit. Data published from 2014 to 2018 were collected and the statistics are shown in Table 3. It was found that there was a sufficient correlation between the input and output factors through correlation analysis (Table 4.).

Table 3: Descriptive statistics of input and output factors

(unit: hundred million won)

\begin{tabular}{|c|c|c|c|c|c|c|}
\hline Factor & Statistics & 2014 & 2015 & 2016 & 2017 & 2018 \\
\hline \multirow{4}{*}{ Asset } & Max & 8,012 & 7,807 & 8,100 & 8,221 & 7,975 \\
\hline & Min & 142 & 165 & 179 & 172 & 205 \\
\hline & Ave & 1,860 & 2,067 & 1,960 & 1,888 & 1,880 \\
\hline & SD & 2,382 & 2,419 & 2,313 & 2,409 & 2,275 \\
\hline \multirow{4}{*}{ Liabilities } & Max & 2,204 & 2,330 & 2,257 & 2,290 & 3,315 \\
\hline & Min & 25 & 29 & 44 & 32 & 37 \\
\hline & Ave & 549 & 679 & 573 & 565 & 570 \\
\hline & SD & 777 & 910 & 765 & 781 & 836 \\
\hline \multirow{4}{*}{ Capital } & $\operatorname{Max}$ & 6,405 & 6,404 & 6,611 & 6,751 & 6,426 \\
\hline & Min & 91 & 130 & 126 & 133 & 139 \\
\hline & Ave & 1,311 & 1,388 & 1,387 & 1,322 & 1,310 \\
\hline & SD & 1,785 & 1,707 & 1,721 & 1,784 & 1,656 \\
\hline \multirow{4}{*}{ Sales } & Max & 7,448 & 7,503 & 7,598 & 7,568 & 7,055 \\
\hline & Min & 67 & 75 & 85 & 86 & 87 \\
\hline & Ave & 1,753 & 1,766 & 1,781 & 1,800 & 1,521 \\
\hline & SD & 2,592 & 2,616 & 2,554 & 2,546 & 2,170 \\
\hline \multirow{4}{*}{$\begin{array}{l}\text { Operational } \\
\text { Profit }\end{array}$} & Max & 382 & 460 & 455 & 471 & 333 \\
\hline & Min & -23 & -48 & -54 & -54 & -46 \\
\hline & Ave & 86 & 95 & 110 & 105 & 86 \\
\hline & SD & 102 & 128 & 157 & 157 & 110 \\
\hline \multirow{4}{*}{ Net Profit } & Max & 460 & 911 & 445 & 407 & 219 \\
\hline & Min & -81 & -94 & -161 & -80 & -44 \\
\hline & Ave & 89 & 130 & 74 & 80 & 56 \\
\hline & SD & 134 & 249 & 144 & 137 & 79 \\
\hline
\end{tabular}


Table 4: Correlation analysis

\begin{tabular}{|c|c|c|c|c|c|c|}
\hline Factor & Asset & Liabilities & Capital & Sales & $\begin{array}{c}\text { Operational } \\
\text { Profit }\end{array}$ & $\begin{array}{c}\text { Net } \\
\text { Profit }\end{array}$ \\
\hline Asset & 1 & $0.8233^{* *}$ & $0.9581^{* *}$ & $0.9576^{* *}$ & $0.8148^{* *}$ & $0.8057^{* *}$ \\
\hline Liabilities & 1 & $0.6263^{* *}$ & $0.8716^{* *}$ & $0.7929^{* *}$ & $0.7592^{* *}$ \\
\hline Capital & & & 1 & $0.8755^{* *}$ & $0.7191^{* *}$ & $0.7237^{* *}$ \\
\hline Sales & & & & 1 & $0.8797^{* *}$ & $0.8727^{* *}$ \\
\hline $\begin{array}{c}\text { Operational } \\
\text { Profit }\end{array}$ & & & & & 1 & $0.9723^{* *}$ \\
\hline Net Profit & & & & & & 1 \\
\hline
\end{tabular}

** The correlation is significant at the 0.01 level (bilateral).

\subsection{Static efficiency analysis}

In this study, CCR-I and BCC-I models were used among DEA models to analyze the static efficiency of domestic Edu-Tech companies. Using the collected data of 15 Edu-Tech companies, the results of finding the efficiency and reference frequency in 2018 are shown in Table 5., and the results of scale efficiency (SE) and return to scale (RTS) are shown in Table 4. DEA-SOLVER software was used for analysis (Cooper,2006).

In the CCR-I model, three relatively effective DMUs (D06, D10, D15), and the remaining 12 DMUs were evaluated as inefficient. In the BCC-I model, seven DMUs (D01, D02, D04, D06, D09, D10, and D15) were effective, and the remaining eight DMUs were evaluated as inefficient. In both models, the relative efficiency was independent of the size of DMU's sales.

In Table 6, the cause of the inefficiency of an inefficient DMU can be identified through SE (scale efficiency). It is interpreted that the closer the SE value is to '1', the closer it is to the optimal scale. If the DMU is completely efficient with the value of ' 1 ' in the BCC model, but the efficiency score is less than ' 1 ' in the CCR model, it is efficient in operation, but inefficient in the DMU scale. In other words, it can be interpreted that overall inefficiency is due to scale. In this sense, DMU D06, D10, and D15 are optimal scales, while DMU D01, D02, D04, and D09 are efficient in operation, but cannot be considered to operate efficiently overall due to their scale. It can be seen that the remaining DMUs D01, D02, D03, D05, D07, D08, D11, D12, D13, and D14 are both inefficient in scale and operational efficiency.

Also in Table 6, RTS (Return to Scale) can be used to make judgments on the scale-up, down, and maintenance. If an inefficient DMU is in the IRS state, the marginal profit increases as the input factor increases, so the scale can be increased to improve efficiency. Can be reduced to improve efficiency. As a result of the analysis, there are 9, 4, and 2 DMUs in IRS, CRS, and DRS, respectively. 
Table 5: The efficiency of Edu-Tech company (2018)

\begin{tabular}{|c|c|c|c|c|c|c|}
\hline \multirow{2}{*}{ DMU } & \multicolumn{2}{|c|}{ CCR } & \multicolumn{2}{c|}{ BCC } & \multicolumn{2}{c|}{$\begin{array}{c}\text { Reference } \\
\text { Frequency }\end{array}$} \\
\cline { 2 - 7 } & SCORE & RANK & SCORE & RANK & CCR & BCC \\
\hline D01 & 0.2468 & 15 & 1 & 1 & & 4 \\
\hline D02 & 0.7902 & 6 & 1 & 1 & & 0 \\
\hline D03 & 0.8912 & 5 & 0.9219 & 8 & & \\
\hline D04 & 0.5274 & 11 & 1 & 1 & & 6 \\
\hline D05 & 0.3731 & 14 & 0.4225 & 15 & & \\
\hline D06 & 1 & 1 & 1 & 1 & 12 & 8 \\
\hline D07 & 0.656 & 8 & 0.8873 & 9 & & \\
\hline D08 & 0.4301 & 13 & 0.5905 & 13 & & \\
\hline D09 & 0.9075 & 4 & 1 & 1 & & 0 \\
\hline D10 & 1 & 1 & 1 & 1 & 2 & 2 \\
\hline D11 & 0.5127 & 12 & 0.5722 & 14 & & \\
\hline D12 & 0.5863 & 10 & 0.7865 & 10 & & \\
\hline D13 & 0.5949 & 9 & 0.7267 & 12 & & \\
\hline D14 & 0.715 & 7 & 0.7736 & 11 & & \\
\hline D15 & 1 & 1 & 1 & 1 & 1 & 2 \\
\hline
\end{tabular}

\subsection{Dynamic efficiency analysis}

In this study, DEA / Window model was used to analyze the dynamic efficiency of Edu-Tech companies in Korea. Table 5. shows the results of CCR efficiency by collecting data from 15 Edu-Tech companies for 5 years from 2014 to 2018. Here, the total number of DMUs ( $\mathrm{n}$ ) is 15 , the total comparison period (k) is 5 years, and the length (p) of the window is determined by 3 by equation (2), so the number of windows $(\mathrm{w}=\mathrm{k}-\mathrm{p}+1)$ is 3 , and the number of DMUs ( $\mathrm{x} \mathrm{p}$ ) for each window is 45 . The total number of DMUs ( $\mathrm{n} \times \mathrm{p} \mathrm{x} \mathrm{w}$ ) is 135 .

When the length of the window is increased, the number of DMUs used for analysis for each window is maximized, so that the degree of freedom increases, especially when the number of DMUs is small. On the other hand, if the length of the window is shortened, the number of windows increases, and there is little difference in static analysis and results. On the other hand, the length of the window has different result values depending on whether the window is included at a specific time.

In Table 7, the average is the average of the efficiency of each Edu-Tech company for 3 years for each window. The average and SD (standard deviation) are the averages and standard deviation of the three window means. And LDY (the 
largest difference between scores in the same year) is the efficiency value of each Edu-Tech company in the same year.

The maximum value of the difference means the largest difference between scores across the entire period (LDP) and the difference between the maximum value and the minimum value of the overall period efficiency value. By analyzing SD, LDY, and LDP values, it is possible to understand the stability of Edu-Tech companies' efficiency in the past 5 years.

First, the DMU with the smallest SD value is D09, and the efficiency of each window is the most stable. The DMU with the largest SD value is D11, and the efficiency of each window is the most unstable. The DMU with the smallest LDY value is D11, which is the most stable by year, while D07 has the largest LDY, so it can be interpreted that the efficiency by year is the most unstable. On the other hand, the LPD value is the smallest change in DMU D09, and the largest change in efficiency in D11 is the largest.

Table 6: The result of SE and RTS

\begin{tabular}{|c|c|c|c|c|}
\hline \multirow{2}{*}{ DMU } & \multicolumn{2}{|c|}{ SCORE } & \multirow{2}{*}{ SE } & \multirow{2}{*}{ RTS } \\
\cline { 2 - 4 } & CCR & BCC & & \\
\hline D01 & 0.2468 & 1 & 0.2468 & IRS \\
\hline D02 & 0.7902 & 1 & 0.7902 & DRS \\
\hline D03 & 0.8912 & 0.9219 & 0.9667 & CRS \\
\hline D04 & 0.5274 & 1 & 0.5274 & IRS \\
\hline D05 & 0.3731 & 0.4225 & 0.8831 & IRS \\
\hline D06 & 1 & 1 & 1 & CRS \\
\hline D07 & 0.656 & 0.8873 & 0.7393 & IRS \\
\hline D08 & 0.4301 & 0.5905 & 0.7284 & IRS \\
\hline D09 & 0.9075 & 1 & 0.9075 & DRS \\
\hline D10 & 1 & 1 & 1 & CRS \\
\hline D11 & 0.5127 & 0.5722 & 0.8960 & IRS \\
\hline D12 & 0.5863 & 0.7865 & 0.7455 & IRS \\
\hline D13 & 0.5949 & 0.7267 & 0.8186 & IRS \\
\hline D14 & 0.715 & 0.7736 & 0.9243 & IRS \\
\hline D15 & 1 & 1 & 1 & CRS \\
\hline
\end{tabular}

From Table 7, to grasp the trend of efficiency change for all 15 DMUs in the last 4 years, the average of the efficiency for each window was obtained and shown in Table 8. and Figure 1. 
Table 7: The summary of Edu-Tech companys' DEA/Window analysis

\begin{tabular}{|c|c|c|c|c|c|c|c|c|c|}
\hline DMU & 2014 & 2015 & 2016 & 2017 & 2018 & Ave. & SD & LDY & LPD \\
\hline \multirow{3}{*}{ D01 } & 0.7361 & 0.3327 & 0.2683 & & & 0.4457 & \multirow{3}{*}{0.1580} & \multirow{3}{*}{0.0915} & \multirow{3}{*}{0.5542} \\
\hline & & 0.4243 & 0.3421 & 0.2796 & & 0.3487 & & & \\
\hline & & & 0.3421 & 0.2796 & 0.1818 & 0.2678 & & & \\
\hline \multirow{3}{*}{ D02 } & 0.6008 & 0.5726 & 0.5057 & & & 0.5597 & \multirow{3}{*}{0.0617} & \multirow{3}{*}{0.1575} & \multirow{3}{*}{0.2244} \\
\hline & & 0.7301 & 0.6448 & 0.5940 & & 0.6563 & & & \\
\hline & & & 0.6448 & 0.5940 & 0.5822 & 0.6070 & & & \\
\hline \multirow{3}{*}{ D03 } & 0.6008 & 0.5726 & 0.5057 & & & 0.5597 & \multirow{3}{*}{0.1333} & \multirow{3}{*}{0.1575} & \multirow{3}{*}{0.4747} \\
\hline & & 0.7301 & 0.6448 & 0.5940 & & 0.6563 & & & \\
\hline & & & 0.6448 & 0.5940 & 0.2553 & 0.4980 & & & \\
\hline \multirow{3}{*}{ D04 } & 0.2170 & 0.1754 & 0.1310 & & & 0.1745 & \multirow{3}{*}{0.0253} & \multirow{3}{*}{0.0297} & \multirow{3}{*}{0.0860} \\
\hline & & 0.1457 & 0.1461 & 0.1514 & & 0.1477 & & & \\
\hline & & & 0.1461 & 0.1514 & 0.1685 & 0.1553 & & & \\
\hline \multirow{3}{*}{ D05 } & 0.1870 & 1.0000 & 0.1317 & & & 0.4396 & \multirow{3}{*}{0.3913} & \multirow{3}{*}{0.0915} & \multirow{3}{*}{0.9127} \\
\hline & & 1.0000 & 0.1091 & 0.0873 & & 0.3988 & & & \\
\hline & & & 0.1148 & 0.0873 & 0.0900 & 0.0974 & & & \\
\hline \multirow{3}{*}{ D06 } & 0.4033 & 0.4789 & 0.5602 & & & 0.4808 & \multirow{3}{*}{0.1199} & \multirow{3}{*}{0.1728} & \multirow{3}{*}{0.3334} \\
\hline & & 0.6106 & 0.7153 & 0.6877 & & 0.6712 & & & \\
\hline & & & 0.7330 & 0.6877 & 0.7367 & 0.7191 & & & \\
\hline & 1.0000 & 1.0000 & 0.5053 & & & 0.8351 & & & \\
\hline D07 & & 1.0000 & 0.5870 & 0.5785 & & 0.7218 & 0.2229 & 0.3558 & 0.5358 \\
\hline & & & 0.8610 & 0.7413 & 0.4642 & 0.6889 & & & \\
\hline & 0.3963 & 0.3918 & 0.2085 & & & 0.3322 & & & \\
\hline D08 & & 0.4570 & 0.2658 & 0.3106 & & 0.3445 & 0.0775 & 0.0652 & 0.2485 \\
\hline & & & 0.2658 & 0.3106 & 0.3169 & 0.2978 & & & \\
\hline & 0.3144 & 0.3627 & 0.3461 & & & 0.3411 & & & \\
\hline D09 & & 0.3403 & 0.3339 & 0.3256 & & 0.3333 & 0.0148 & 0.0224 & 0.0484 \\
\hline & & & 0.3339 & 0.3256 & 0.3189 & 0.3261 & & & \\
\hline & 0.5740 & 0.4880 & 0.3523 & & & 0.4714 & & & \\
\hline D10 & & 0.4053 & 0.3891 & 0.4294 & & 0.4080 & 0.0724 & 0.0827 & 0.2217 \\
\hline & & & 0.4245 & 0.4679 & 0.5424 & 0.4783 & & & \\
\hline & 1.0000 & 0.0425 & 0.0949 & & & 0.3791 & & & \\
\hline D11 & & 0.0535 & 0.0807 & 1.0000 & & 0.3781 & 0.4523 & 0.0141 & 0.9575 \\
\hline & & & 0.0807 & 1.0000 & 0.2895 & 0.4567 & & & \\
\hline & 0.2738 & 0.2517 & 0.3027 & & & 0.2760 & & & \\
\hline D12 & & 0.3209 & 0.3860 & 0.4111 & & 0.3727 & 0.0664 & 0.0833 & 0.1803 \\
\hline & & & 0.3860 & 0.4111 & 0.4319 & 0.4097 & & & \\
\hline & 0.4218 & 0.4373 & 0.3210 & & & 0.3934 & & & \\
\hline D13 & & 0.5103 & 0.3753 & 0.3015 & & 0.3957 & 0.0721 & 0.1001 & 0.2088 \\
\hline & & & 0.4211 & 0.3015 & 0.4383 & 0.3870 & & & \\
\hline
\end{tabular}




\begin{tabular}{|c|c|c|c|c|c|c|c|c|c|}
\hline DMU & 2014 & 2015 & 2016 & 2017 & 2018 & Ave. & SD & LDY & LPD \\
\hline \multirow{3}{*}{ D14 } & 0.2349 & 0.2403 & 0.2803 & & & 0.2518 & \multirow{3}{*}{0.0552} & \multirow{3}{*}{0.0771} & \multirow{3}{*}{0.1605} \\
\hline & & 0.3064 & 0.3574 & 0.3381 & & 0.3340 & & & \\
\hline & & & 0.3574 & 0.3381 & 0.3953 & 0.3636 & & & \\
\hline \multirow{3}{*}{ D15 } & 0.2716 & 0.3354 & 0.2694 & & & 0.2921 & \multirow{3}{*}{0.0798} & \multirow{3}{*}{0.0741} & \multirow{3}{*}{0.2180} \\
\hline & & 0.3688 & 0.3435 & 0.1508 & & 0.2877 & & & \\
\hline & & & 0.3435 & 0.1622 & 0.2440 & 0.2499 & & & \\
\hline
\end{tabular}

In Table 8. And Figure 1, the average for each window is the highest in DMU D07 and the lowest in D04. In the variation through the window, the upward trend of efficiency was the steepest in DMU D06, and the steepest downward trend in D05.

Table 8: Variation through window

\begin{tabular}{|c|c|c|c|c|c|}
\hline & $\mathbf{1 4 - 1 5 - 1 6}$ & $\mathbf{1 5 - 1 6 - 1 7}$ & $\mathbf{1 6 - 1 7 - 1 8}$ & Ave. & Rank \\
\hline D01 & 0.4457 & 0.3487 & 0.2678 & 0.3541 & 8 \\
\hline D02 & 0.5597 & 0.6563 & 0.6070 & 0.6076 & 3 \\
\hline D03 & 0.5597 & 0.6563 & 0.4980 & 0.5713 & 4 \\
\hline D04 & 0.1745 & 0.1477 & 0.1553 & 0.1592 & 15 \\
\hline D05 & 0.4396 & 0.3988 & 0.0974 & 0.3119 & 13 \\
\hline D06 & 0.4808 & 0.6712 & 0.7191 & 0.6237 & 2 \\
\hline D07 & 0.8351 & 0.7218 & 0.6889 & 0.7486 & 1 \\
\hline D08 & 0.3322 & 0.3445 & 0.2978 & 0.3248 & 11 \\
\hline D09 & 0.3411 & 0.3333 & 0.3261 & 0.3335 & 10 \\
\hline D10 & 0.4714 & 0.4080 & 0.4783 & 0.4526 & 5 \\
\hline D11 & 0.3791 & 0.3781 & 0.4567 & 0.4047 & 6 \\
\hline D12 & 0.2760 & 0.3727 & 0.4097 & 0.3528 & 9 \\
\hline D13 & 0.3934 & 0.3957 & 0.3870 & 0.3920 & 7 \\
\hline D14 & 0.2518 & 0.3340 & 0.3636 & 0.3165 & 12 \\
\hline D15 & 0.2921 & 0.2877 & 0.2499 & 0.2766 & 14 \\
\hline & & & & & \\
\hline
\end{tabular}

In conclusion, DMU D05 and D07 showed a steep decline in efficiency. In the case of D03, the efficiency decreased again after rising, so it is necessary to identify the cause of the efficiency drop and respond quickly. In the case of DMU D04, the fluctuation is not large, but the efficiency is significantly low, so efforts to overcome low efficiency are required.

In conclusion, DMU D05 and D07 showed a steep decline in efficiency. In the case of D03, the efficiency decreased again after rising, so it is necessary to identify 
the cause of the efficiency drop and respond quickly. In the case of DMU D04, the fluctuation is not large, but the efficiency is significantly low, so efforts to overcome low efficiency are required.

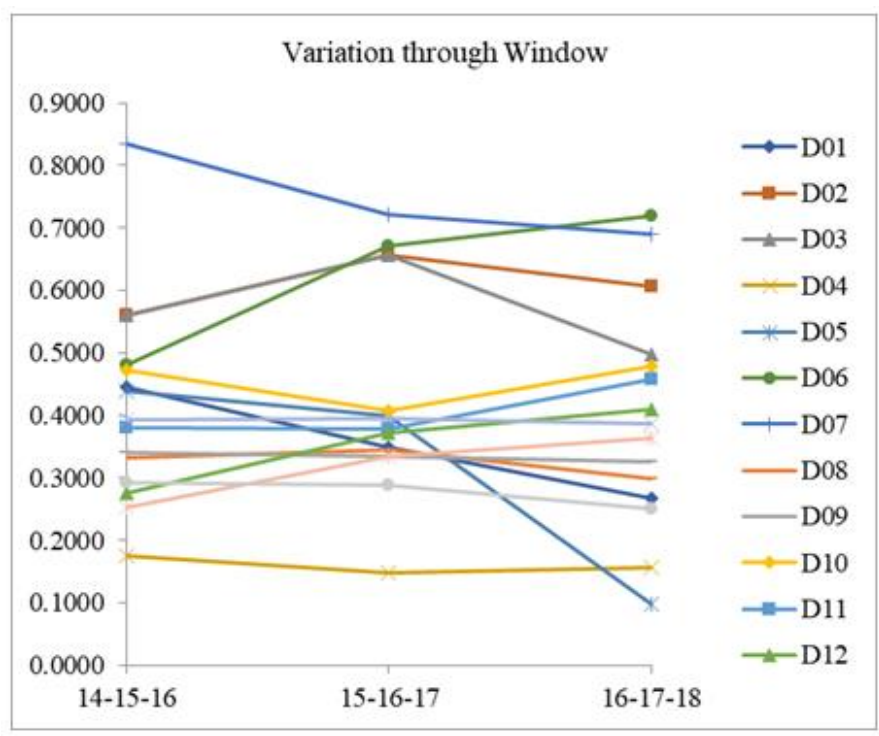

Fig. 1: Variation through window

\section{Conclusion}

As the 4th Industrial Revolution entered, Edu-Tech companies that incorporated ICT technology into the education industry are also increasing in Korea and abroad. For Edu-Tech companies, a new business area, to continue, they must constantly increase their competitiveness. In particular, to generate more output with limited resources, efficiency must be relatively high. The purpose of this study is to provide a means to improve the efficiency and efficiency of inefficient companies by analyzing and evaluating the static/dynamic efficiency of domestic Edu-Tech companies.

By analyzing the static efficiency, it is possible to evaluate whether one's own company is relatively efficient compared to other companies and to select the targets to be benchmarked. It also allowed inefficient companies to determine whether the cause of inefficiency was due to scale, operation, or both, and suggested a direction to resize the scale if it was related to scale.

In addition, after collecting data over several periods, dynamic efficiency was analyzed to observe changes in efficiency. By deciding the window and evaluating the trend and volatility of efficiency, it proposed to establish countermeasures for companies with upward / downward trends, companies with large changes in efficiency, and companies with low efficiency. 


\section{Acknowledgment}

This research was supported by Seokyeong University in 2019.

\section{References}

Banker, R. D. and Cooper W. W. (1984). Some models for estimating technical and scale inefficiencies in data envelopment analysis. Management Science, 39(9), 1078-1092.

Banker, R. D., Cooper, W. W., Seiford, L.M., Thrall, R.M. and Zhu J. (2004). Returns to scale in different DEA models. European Journal of Operational Research, 154, 345-362.

Charnes, A., Clark, C. T., Cooper, W. W. and Golany, B. (1985). A developmental study of data envelopment analysis in measuring the efficiency of maintenance units in the U.S. Air Forces. Annals of Operations Research, 2, 95-112.

Charnes, A. and Cooper W. W. (1985). Preface to topics in data envelopment analysis. Annals of Operation Research, 2, 59-94.

Charnes, A., Cooper W. W. and Rhodes E. (1978). Measuring the efficiency of decision making units". European Journal of Operation Research, 2(6), 429-444.

Cook, W. D., Tone, K. and Zhu J. (2014). Data envelopment analysis: prior to choosing a model. Omega, 44, 1-4.

Cooper, W. W., Seiford, L. M. and Tone K. (2006). Data envelopment analysis: A comprehensive text with models, applications, references and DEA-Solver software. Second Edition, Springer, New York.

Dora L. (2018), Education in Professional Defense - Possibilities of Classification of Training Level with the Help of Impulse, Journal of System and Management Sciences, Vol. 8, No. 1, 23-44.

Fitzsimmons, J. A. and Fitzsimmons M. J. (1994). Service management for competitive advantage. McGrow-Hill Inc.

Goh H. W. (2016). A study on evaluating management productivity for logistics-IT Corporations. Advanced Science and technology Letters (Information Technology and Computer Science 2016), SERSC, 133, 201- 206.

Goh H.W. (2015). The efficiency comparative evaluation of IT service companies using the data envelopment analysis approach focus on KOSDAQ(KOrea Securities 
Dealers Automated Quotations) companies. International Journal of Software Engineering and Its Applications, 9(5), 205-218.

Dilogini K., Shivany S. \& Kumara A. (2019), Analysis of Relation Between Customer Behavior and Information Technology Market, Journal of System and Management Sciences, Vol. 9, No. 1, 87-104.

Nedaei, H., Naini, S. G. J. and Makui A. (2020). A dynamic DEA model to measure the learning rates of efficient frontier and DMUs: an application to oil and gas wells drilling. Computers \& Industrial Engineering, 144, 1-14.

STEPI (2019). Education after one generation-public and private education. Future Horizon+, 30(3), 40-45.

Zarbi, S., Shin, S. H. and Shin U. J. (2019). An analysis by window DEA on the influence of international sanction to the efficiency of Iranian container ports. The Asian Journal of Shipping and Logistics, 35(4), 163-171. 